\title{
AUTONOMIC SEIZURES AND DÉJÀ VU IN A PATIENT WITH GANGLIOCYTOMA OF THE ORBITOFRONTAL CORTEX
}

\author{
Helena Šarac ${ }^{1}$ Željka Petelin-Gadže ${ }^{2}$, Goran Pavliša ${ }^{3}$, Sanja Perić ${ }^{4}$, Marija Bošnjak-Pašić ${ }^{5}$, \\ Hanna Pašić ${ }^{6} \&$ Neven Henigsberg ${ }^{7}$ \\ ${ }^{I}$ Center of Excellence for Basic and Translational Neuroscience, Medical School University of Zagreb, \\ Department of Neurology, University Hospital Center Zagreb, Zagreb, Croatia \\ ${ }^{2}$ Department of Neurology, University Hospital Centre Zagreb, School of Medicine, University of Zagreb, \\ Referral Centre for Epilepsy, Ministry of Health of the Republic of Croatia, Zagreb, Croatia \\ ${ }^{3}$ Clinical Institute of Radiology, University Hospital Center Zagreb, Zagreb, Croatia \\ ${ }^{4}$ Department of Ophtalmology, University Hospital Center Zagreb, Zagreb, Croatia \\ ${ }^{5}$ Medical School University of Osijek, University Hospital Center Zagreb, Department of Neurology, Zagreb, Croatia \\ ${ }^{6}$ Medical School University of Zagreb, Zagreb, Croatia \\ ${ }^{7}$ Medical School University of Zagreb, Croatian Institute for Brain Research, Zagreb, Croatia
}

received: 17.4.2018;

revised: 4.6.2018;

accepted: 6.6.2018

$* * * * *$

\section{INTRODUCTION}

Although autonomic auras are commonly believed to reflect temporal lobe dysfunction, several reports suggest that orbitofrontal cortex may play a key role in the pathogenesis of autonomic seizures. The clinical manifestations of focal seizures of orbitofrontal origin have not been well defined because of the limited number of seizure-free cases. Although no specific auras or seizures were not found that exclusively characterised the orbitofrontal area as the seizure focus, orbitofrontal seizures usually include psychoaffective phenomena, hallucinations, unpleasant feeling, flashbacks, taste sensations, cephalic sensations, olfactory, light-headedness, body tingling, fuzzy vision et al. Proposed psychic, autonomic and olfactory symptoms are difficult to identify clinically and electrographycally (Smith et al. 2004, Fisher et al. 2017). The déjà vu (DV) phenomenon (French for "already seen") occurs in most healthy individuals, but it can be a sign of temporal lobe epilepsy (TLE), certain psychiatric diseases, and it can be an early symptom of a mass lesion of the brain (Bošnjak Pašić et al. 2018, Vlasov et al. 2013), This report presents the clinical, neuroimaging and electroencephalographic findings in a patient with déjà vu phenomenon, who developed autonomic seizures and due to a gangliocytoma involving the orbitofrontal region.

\section{CASE DESCRIPTION}

A 69-year-old woman without significant medical history developed autonomic symptoms for three months. The patient complained of chest and abdominal discomfort, epigastric warmth arising into her chest, neck and face, nausea, palpitations, shortness of breath and lightheadedness, fear and stomach butterflies. Epigastric/visceral sensation have had abrupt onset, occured several times per day, lasting 30-60 $\mathrm{s}$ and were typical of autonomic type of aura according to the classification of seizure types by the International League Against Epilepsy (ILAE) (Fisher et al. 2017). All seizures remained focal, without impaired awareness. Since the 25 years of age, the patient has been experiencing déjà vu (DV) episodes which occured once per week, such as perceiving things as already seen in the same circumstances, lasting up to $10 \mathrm{~s}$. Déjà vu phenomenon decreased with age and has occured once per month, lasting up to $5 \mathrm{~s}$, and were unrelated to autonomic seizures. Déjà $\mathrm{vu}$ episodes were usually accompanied by pleasant feelings, and the patient was willing to relive the experience. Neurological examination was normal. Brain magnetic resonance imaging (MR 3.0T) revealed discrete calcified contrast-enhanced cystic lesion localized in the left orbitofrontal area (Fig1 A-D). Normal MR spectra were obtained from the lesion. Routine electroencephalography (Figure 1, E) showed normal background activity. Theta rhytms and sharp-waves were registered over the left fronto-temporo-basal area. Intermitent tendency of paroxysmal discharges were unaccompanied by clinical manifestations. The patient refused pre-surgical prolonged video-EEG monitoring (VEM). The patient was diagnosed with orbitofrontal epilepsy (classification symptomatic focal autonomic seizures) accompanied with dysmnesic symptoms involving a déjà vu. Treatment with oxycarbamazepine (900 mg per day) was administered, but epileptic seizures were not completely controlled. The patient underwent brain surgery. Post-surgical histological examination indicated gangliocytoma. Following removal of the tumor, the dose of oxycarbamazepine was decreased to $600 \mathrm{mg}$ per day. In the past 18 months, the patient has not experienced autonomic seizures, while déjà vu phenomenon occured on a monthly basis. 

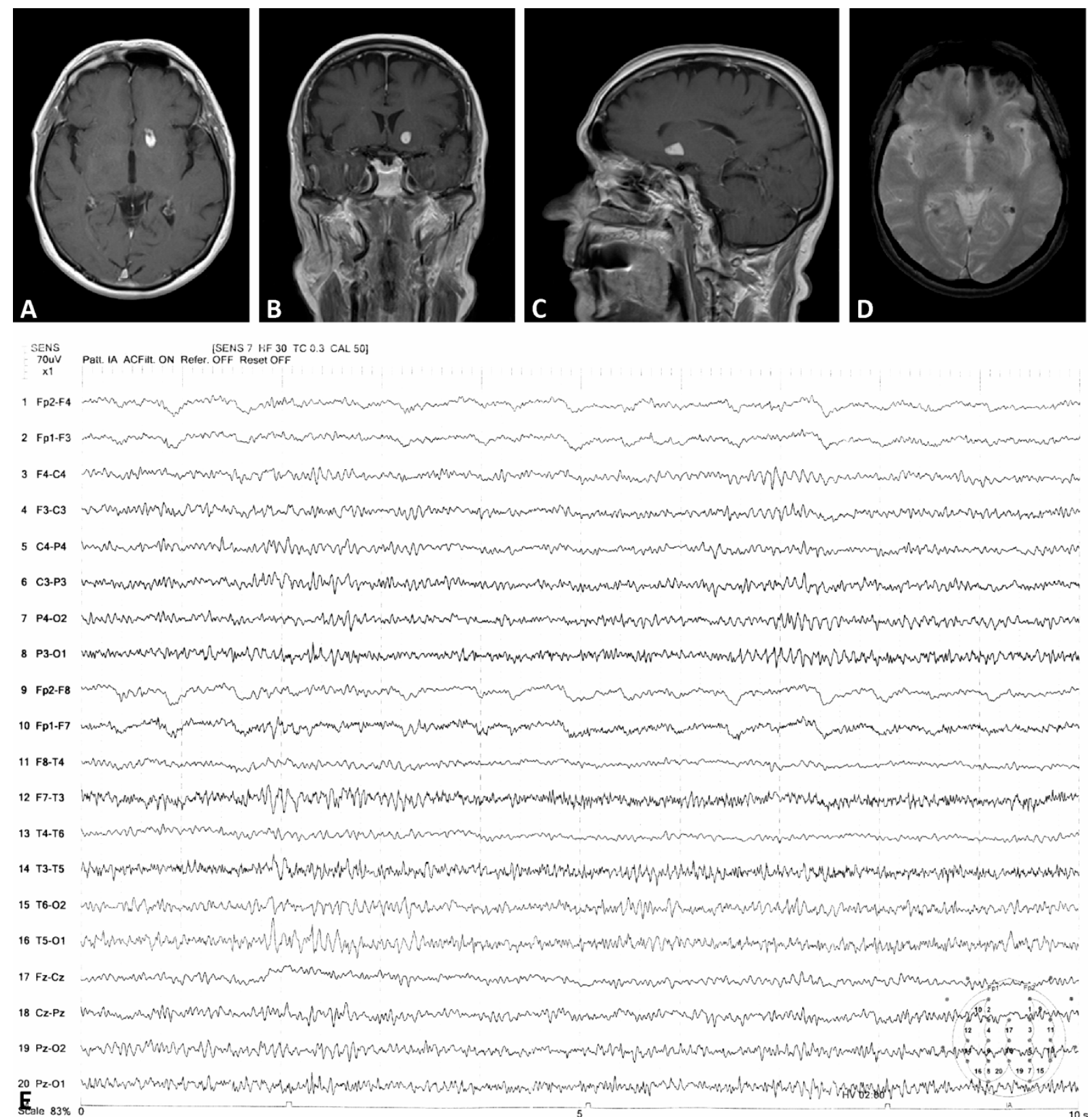

Figure 1. (A-E). MRI in T1W; axial (A); coronal (B); sagittal plane (C); and axial T2W (D) shows a gangliocytoma in the left orbitofrontal region. Electroencephalography registered theta rhytm and sharp-waves over the left frontotemporo-basal area with paroxysmal tendency $(\mathrm{E})$.

\section{DISCUSSION}

There are exceptionally rare reports linking the discrete structural lesion of the orbitofrontal area with autonomic symptoms. Authors performed literature search and presented two patients with orbitofrontal epilepsy (Smith et al. 2004). The authors identified two lesional and two nonlesional patients who were seizurefree several years after epilepsy surgery.(Rougier and Loiseal 1988, Chang et al. 1991) One lesional patient had gliosis consistent with lipofuscinosis, (Chang et al. 1991) and another case underwent complete resection of the old postraumatic hematoma cavity (Rougier and Loiseal 1988). Rougier and Loiseal presented a case of nonlesional orbitofrontal epilepsy in whom the disap- pearance of seizures after surgical resection limited to the orbitofrontal cortex confirmed the anatomic site of the epileptic focus. Focal seizure without impaired awareness were noted in two of these four cases and were similar to mesial temporal origin including gustatory, head tingle and déjà vu sensations in one case (Smith et al. 2004) and body numb, flashbacks, fear and stomach butterflies in another case (Rougier and Loiseal 19988). The right frontal lobe surgery resulted in seizure freedom and resolution of visual hallucinations and psychosis also in a patient with histologically defined cortical dysplasia reported by La Vega-Talbot et al. 2006. Unresponsiveness (absence) was noted in the case of Chang et al. and only partially in the case of Rougier and Loiseal. In the present case of patient, focal seizure without 
impaired awareness (aura) was noted, while absence and automatisms have not been observed. Furthermore, contrasted to all of the reported orbitofrontal seizure cases, epigastric sensations and DV phenomenon were observed in the current patient. This supports hypothesis proposed by Smith which suggest that seizures of orbitofrontal origin without alteration of consciousness probably have more limited spreading of epileptiform activity, as it was found in the presented case with discrete tumorous lesion of the orbitofrontal location. This patient is also unique due to histological characteristic of the structural lesion underlying orbitofrontal seizure. Gangliocytomas usually occured in young patients with a history of drug-resistant epilepsy and have calcified cystic lesion in the temporal lobe or the cerebellum.

Close temporal relationship between seizure freedom and surgical resection of the gangliocytoma and the earlier proposed mechanism together with other cases strongly support the hypothesis of orbitofrontal cortex involvement in the patophysiology of simple partial autonomic seizures and did seem to differentiate seizures of orbitofrontal origin from those in anterior cingulate or other areas of the prefrontal cortex. Déjà vu phenomenon in this patient was characterized by a nonspecific pattern of EEG activity, had low frequency and low duration, and occured mostly as an psychological phenomenon, usually induced by fatigue or sleep. However, such nonpathological DV might be associated with altered neuron functioning, probably restricted to a small area within the parahippocampal zone that it does not produce any distinctive EEG pattern (Bošnjak Pašić et al. 2018, Vlasov et al. 2013). Episodes of DV phenomenon probably occur as a result of an impaired connection between the neocortex and the mesiotemporal structures when the cortical activity weakens. Nonpathologicalnonepileptic DV type does not show an epileptiform EEG pattern, has low frequency and low duration, and occurs mostly as an induced phenomenon (Bošnjak Pašić et al. 2018, Vlasov et al. 2013).

\section{CONCLUSION}

We presented a case of one lesional orbitofrontal epilepsy in whom the disappearance of autonomic seizures after surgical resection limited to the orbitofrontal cortex confirmed the anatomic site of the epileptic focus. Our study also identified probably nonpathological déjà vu phenomenon which is not characteristic of patients with epilepsy and it may be basically a psychological phenomenon.

\section{Acknowledgements:}

This publication was co-financed by the Croatian Science Foundation under the project number IP-2014-09-2979 and the European Union through the European Regional Development Fund, Operational Programme Competitiveness and Cohesion, grant agreement No. KK.01.1.1.01.0007, CoRE Neuro.

\section{Conflict of interest: None to declare.}

\section{Contribution of individual authors:}

Helena Šarac had full access to all of the data in the study and takes responsibillity for the integrity of the data and the accuracy of the data analysis;

Study concept and design: Helena Šarac \& Željka Petelin-Gadže;

Acquisition, analysis, or interpretation of data: Helena Šarac, Željka Petelin-Gadže, Goran Pavliša, Marija Bošnjak-Pašić, Hanna Pašić \& Neven Henigsberg;

Drafting of the manuscript: Helena Šarac;

Critical revision of the manuscript for important intellectual content: Helena Šarac, Željka Petelin-Gadže, Goran Pavliša, Sanja Perić, Marija Bošnjak-Pašić, Hanna Pašić \& Neven Henigsberg;

Study supervision: Helena Šarac \& Željka PetelinGadže.

\section{References}

1. Bošnjak Pašić M, Horvat Velić E, Fotak L, Pašić H, Srkalović Imširagić $A$, Milat $D$, Šarac $H$, Bjedov $S \&$ Petelin Gadže Z̃: Many faces of déjà vu: a narrative review. Psychiatr Danub 2018; 30:21-25

2. Chang CN, Ojemann LM, Ojemann GA, Letich E: Seizures of fronto-orbital origin: A proven case. Epilepsia 1991; 32:487-491

3. Fisher RS, Cross H, French JA, et al.: Operational classification of seizure types by the International League Against Epilepsy: Position Paper of the ILAE Commission for Classification and Terminology. Epilepsia 2017; 58:522-530

4. La Vega-Talbot M, Duchowny M, Jayakar P: Orbitofrontal seizures presenting with ictal visual hallucinations and interictal psychosis. Pediatr Neurol 2006; 35:78-81

5. Rougier A, Loiseal P: Orbital frontal epilepsy: A case report. J Neurol Neurosurg Psychiatry 1988; 51:146-147

6. Smith JR, Sillay $K$, Winkler $P$, King $D W$, Loring $D W$ : Orbitofrontal epilepsy: electroclinical analysis of surgical cases and literature review. Stereotact Funct neurosurg 2004; 82:20-5

7. Vlasov PN, Chervyakov AV and Gnezditskii VV: Déjà vu phenomenon-related EEG pattern. Case report. Epilepsy Behav Case Rep 2013; 1:136-141

\section{Correspondence:}

Helena Šarac, $M D, P h D$

Department of Neurology, University Hospital Zagreb

HR-Kispaticeva 12, 10000 Zagreb, Croatia

E-mail: helenasarac57@gmail.com 